patients could improve their lung function, the authors say.

Proc. Natl Acad. Sci. USA

http://doi.org/vbc (2014)

NEUROSCIENCE

\section{Light signals boost stroke recovery}

Mice that have had a stroke regain motor function after specific brain neurons are stimulated by light.

Using a technique called optogenetics, Michelle Cheng, Gary Steinberg and their colleagues at Stanford University in California studied mice that were genetically engineered to express a light-sensitive protein in a group of neurons in the brain's motor cortex.

The team induced a stroke on one side of this area and then activated the engineered neurons by switching on a small, implanted light probe. This stimulation increased blood flow and the levels of various growth factors in the opposite, uninjured cortex.

Moreover, these animals gained more weight and walked faster and farther than unstimulated stroke mice.

Further study of the mechanisms of this recovery could lead to new drug targets or therapy techniques for stroke, the authors say.

Proc. Natl Acad. Sci. USA

http://doi.org/vbj (2014)

\section{LIMNOLOGY}

\section{Earth's lakes added up}

The world is home to 117 million lakes, according to a satellite-based survey.

Lakes are important to the planet's carbon cycle, but researchers have struggled to estimate the number that exist, in part because small lakes have been difficult to count. A team led by Charles Verpoorter of the University of Lille Nord in France used high-resolution imagery from the Landsat satellite to catalogue all lakes larger than 2,000 square metres.
Unlike earlier estimates, the total count is dominated by large and mediumsized lakes, not small ones. Together, the lakes cover about 5 million square kilometres, or 3.7\% of Earth's land not covered by ice. Geophys. Res. Lett. http://doi. org/t9v (2014)

Polio killed the
vaccinated

The poliovirus strain that caused an outbreak in the Republic of the Congo in 2010 is able to resist the immune responses generated by a commonly used vaccine. The finding could explain why the outbreak, which killed nearly half of the 445 people infected, was so severe.

Christian Drosten at the University of Bonn Medical Centre in Germany and his colleagues analysed the virus strain responsible for the outbreak. They found a combination of two mutations, both in the proteins of the strain's 'coat', which make it harder for certain antibodies to stick to the virus. People who died in this outbreak had been vaccinated in the past, but people who were freshly re-vaccinated could fight off the virus.

The authors warn that other resistant strains could emerge, even as the world is close to eradicating the disease.

Proc. Natl Acad. Sci. USA

http://doi.org/vbg (2014)

\section{ENVIRONMENTAL MICROBIOLOGY}

\section{Algal boom and bust tracked}

Viruses that infect and kill algae could influence the ocean carbon cycle.

Ilan Koren and Assaf Vardi at the Weizmann Institute of Science in Rehovot, Israel, and their colleagues used satellite imagery to measure the atmospheric carbon absorbed by a roughly 1,000 -squarekilometre algal bloom during its 25-day life cycle in the

SOCIAL SELECTION Romizaricicas

\title{
The cost of misconduct
}

A report detailing the supposedly meagre costs of scientific misconduct has set off an online discussion about the real toll of shoddy science. Using the records of the US government's Office of Research Integrity, researchers led by Ferric Fang at the University of Washington in Seattle collected studies funded by the National Institutes of Health (NIH) that had been retracted because of misconduct from 1992 to 2012 . All told, the NIH had spent about US\$58 million on these projects, less than $1 \%$ of its total budget over this time. On Google+, mathematician Joerg Fliege at the University of Southampton, UK, did what he does best: the maths. "Multiply this figure with 100 if you believe that only $1 \%$ of misconducts get detected," he posted. "Still not much of an expense, in the overall scheme of things."

elife 3, e02956 (2014)

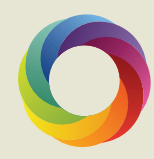

Based on data from altmetric.com Altmetric is supported by Macmillan Science and Education, which owns Nature Publishing Group.

ONATURE.COM

For more on popular papers: go.nature.com/tuaco5
North Atlantic. They found that the algae converted around 22,000 tonnes of atmospheric carbon into organic carbon - about as much as a rainforest of equivalent size - before viruses caused the bloom to collapse.

Two-thirds of this carbon was released back into the atmosphere within a week of the bloom's collapse. The rest could have been transported deep into the ocean, as infected algae sank to the ocean floor, the authors suggest.

Curr. Biol. http://doi.org/vbx (2014)

\section{PLANT SCIENCES \\ Plants drink mineral water}

Thirsty plants can extract water from the crystalline structure of gypsum, a rockforming mineral found in soil on Earth and Mars.

Some plants grow on gypsum outcrops and remain active even during dry summer months, despite having shallow

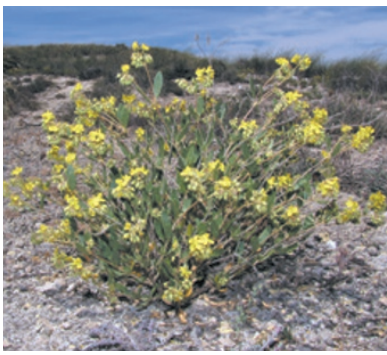

roots that cannot reach the water table. Sara Palacio of the Pyrenean Institute of Ecology in Jaca, Spain, and her colleagues compared the isotopic composition of sap from one such plant, called Helianthemum squamatum (pictured), with gypsum crystallization water and water found free in the soil. The team found that up to $90 \%$ of the plant's summer water supply came from gypsum.

The study has implications for the search for life in extreme environments on this planet and others.

Nature Commun 5, 4660 (2014)

\section{ONATURE.COM}

For the latest research published by Naturevisit:

www.nature.com/latestresearch 